\title{
(inn) Contábil
}

REVISTA AMBIENTE CONTÁBIL

Universidade Federal do Rio Grande do Norte

ISSN 2176-9036

Vol. 10. n. 2, jul./dez. 2018

Sítios: http://www.periodicos.ufrn.br/ambiente

http://www.atena.org.br/revista/ojs-2.2.3-06/index.php/Ambiente

Artigo recebido em: 23.08.2017. Revisado por pares em: 20.12.2017. Reformulado em: 23.01.2018. Avaliado pelo sistema double blind review.

COERÊNCIA NA EVIDENCIAÇÃO DAS PRÁTICAS AMBIENTAIS DAS EMPRESAS LISTADAS NO ÍNDICE DE SUSTENTABILIDADE EMPRESARIAL (ISE)

COHERENCE IN THE DISCLOSURE OF ENVIRONMENTAL PRACTICES OF COMPANIES LISTED ON THE BUSINESS SUSTAINABILITY INDEX (ISE)

COHERENCIA EN LA EVIDENCIA DE LAS PRÁCTICAS AMBIENTALES DE LAS EMPRESAS ENUMERADAS EN EL ÍNDICE DE SOSTENIBILIDAD EMPRESARIAL (ISE)

Autoras:

Bruna Sales

Graduada em Ciências Contábeis - Universidade Federal de Santa Catarina. Endereço: Campus Universitário Reitor João David Ferreira Lima, Trindade, Florianópolis/SC - Brasil, CEP: 88040-900. Telefone: (048) 3721-6517. Identificadores (ID):

Lattes: http://lattes.cnpq.br/8459157718495739

E-mail: bruna_riba@hotmail.com

Suliani Rover

Doutora em Controladoria e Contabilidade pela Universidade de São Paulo - USP. Professora do Programa de Pós-Graduação em Contabilidade - Universidade Federal de Santa Catarina. Endereço: Campus Universitário Reitor João David Ferreira Lima, Trindade, Florianópolis/SC - Brasil, CEP: 88040-900. Telefone: (048) 3721-3892. Identificadores (ID):

Lattes: http://lattes.cnpq.br/6285577163747055 UFSC/PPGC: http://www.ppgc.ufsc.br/corpo-docente/ E-mail: sulianirover@gmail.com

Janaína da Silva Ferreira

Doutoranda em Contabilidade pela Universidade Federal de Santa Catarina. Endereço: Campus Universitário Reitor João David Ferreira Lima, Trindade, Florianópolis/SC - Brasil, CEP: 88040-900. Telefone: (048) 3721-6517 Identificadores (ID):

Lattes: http://lattes.cnpq.br/0779656441337309 Google Citations: https://scholar.google.com/citations?user=2B5iXzAAAAAJ E-mail: janix_17@msn.com 
[Artigo apresentado no ECECON - Encontro Catarinense de Estudantes de Ciências Contábeis - 2017 - UFSC]

\title{
RESUMO
}

O objetivo da pesquisa é analisar se as empresas listadas na BM\&FBOVESPA e que divulgaram suas respostas no Índice de Sustentabilidade Empresarial (ISE) estão respondendo o seu questionário, no âmbito ambiental, de forma coerente com os seus relatórios de sustentabilidade. Metodologicamente, a pesquisa possui caráter descritivo, com abordagem qualitativa. A amostra do estudo é constituída por dezoito empresas do Grupo A que divulgaram suas respostas no questionário de 2013 a 2016, alusivos à dimensão ambiental, em consonância com os seus relatórios de sustentabilidade publicados até 05/2017. Foram analisados os critérios de Política, Gestão, Desempenho e Cumprimento Legal. Como principais resultados, foi observado que no critério Política, as empresas não apresentaram divergências no indicador relacionado ao compromisso, abrangência e divulgação. No critério de Gestão ressalta-se que a relação divergente sobre o nível hierárquico do gestor ambiental foi de $83 \%$ em 2013 e evoluiu gradativamente para 5\% em 2016. O critério Desempenho mudou de 100\% de conformidade em 2013 para 39\% em 2016, no indicador gerenciamento e, monitoramento relacionado a sustentabilidade. Por fim, no critério Cumprimento Legal notou-se uma variabilidade nos resultados, visto que as empresas tendem a não divulgar suas ações e penalidades nos relatórios.

Palavras-chave: Evidenciação Ambiental. Relatório de Sustentabilidade. ISE.

\begin{abstract}
This research aims to verify how the listed companies BM\&FBOVESPA answered the ISE questionnaire, in the environmental aspect, are disseminating this information in their sustainability reports. Methodologically, this study has descriptive character, with a qualitative approach. The study sample consists of eighteen companies from Group A that published their responses in the questionnaire since 2013 to 2016, alluding to the environmental dimension, in line with their sustainability reports published until May 2017. The criteria for Policy, Management, Performance and Legal Compliance. As main results, it was observed that in the Policy criterion, the companies did not present divergences in the indicator related to the commitment, scope and disclosure. The Management criterion shows that the divergent relationship on the hierarchical level of the environmental manager was $83 \%$ in 2013 and evolved positively reaching 5\% divergence in 2016. The Performance criterion changed from 100\% compliance in 2013 to 39\% in 2016, in the management and monitoring indicator related to sustainability. Finally, in the Legal Compliance criterion, a variability was observed in the results, since companies tend not to disclose their actions and penalties in the reports.
\end{abstract}

Keywords: Environmental Evidence. Sustainability Report. ISE.

\section{RESUMEN}

El objetivo de la investigación es analizar si las empresas listadas en la BM \& FBOVESPA y que divulgar sus respuestas en el Índice de Sustentabilidad Empresarial (ISE) están respondiendo su cuestionario, en el ámbito ambiental, de forma coherente con sus informes de sostenibilidad. Metodológicamente, la investigación tiene carácter descriptivo, con abordaje cualitativo. La muestra del estudio está constituida por dieciocho empresas del Grupo A que divulgar sus 
respuestas en el cuestionario de 2013 a 2016, alusivos a la dimensión ambiental, en consonancia con sus informes de sostenibilidad publicados hasta el 05/2017. Se analizaron los criterios de Política, Gestión, Rendimiento y Cumplimiento Legal. Como principales resultados, se observó que en el criterio Política, las empresas no presentaron divergencias en el indicador relacionado al compromiso, alcance y divulgación. En el criterio de Gestión se resalta que la relación divergente sobre el nivel jerárquico del gestor ambiental fue del $83 \%$ en 2013 y evolucionó gradualmente al 5\% en 2016. El criterio Rendimiento cambió del 100\% de conformidad en 2013 al 39\% en 2016, En el indicador de gestión y monitoreo relacionado con la sostenibilidad. Por último, en el criterio Cumplimiento Legal se notó una variabilidad en los resultados, ya que las empresas tienden a no divulgar sus acciones y penalidades en los informes.

Palabras clave: Evidencia Ambiental. Informe de Sostenibilidad. ISE.

\section{INTRODUÇÃO}

O cenário econômico é cerceado de constantes alterações em seu ciclo. Estas alterações são vistas como evolutivas e incluem a sustentabilidade como um aspecto importante para as estratégias definidas no mercado e tornam-se um instrumento de desenvolvimento e crescimento das evidências ambientais nas organizações, que transmitem esse comportamento aos stakeholders e ao meio ambiente. Estas evidências para Ribeiro (2005, p.45) tem por objetivo "identificar, mensurar e esclarecer os eventos econômico-financeiros que estejam relacionados com a preservação, proteção e recuperação ambiental, ocorridos em um determinado período, visando à evidenciação da situação patrimonial da entidade".

Para atender a necessidade de evidenciação das empresas e auxiliar nas iniciativas socioambientais, foi desenvolvido em 2005 o Índice de Sustentabilidade Empresarial (ISE), pela Bolsa de Valores Mercadorias e Futuros de São Paulo (BM\&FBOVESPA). O objetivo do ISE é informar sobre a eficiência econômica, equilíbrio ambiental, justiça social e governança corporativa, criando um ambiente de investimentos harmônicos com as demandas de desenvolvimento da sustentabilidade da sociedade, bem como incentivar a boa prática para as empresas brasileiras (PLETSCH et al., 2014).

As informações ambientais vêm sendo declaradas por parte das empresas apesar de não existirem leis e normas reguladoras que as obriguem a fazê-lo. Contudo, devido ao risco de seleção adversa, as empresas podem evidenciar informações negativas de forma voluntária quando acreditam que serão penalizadas pelos usuários externos pela não divulgação, prejudicando a reputação da companhia e desacreditando seus acionistas (ROVER et al., 2008).

Tendo percebido a importância do aspecto ambiental dentre os quesitos analisados pelo ISE, Pletsch et al. (2014) verificaram os itens que contemplam a evidenciação das práticas ambientais das empresas no questionário do índice. Seus principais resultados apontam que as empresas, em sua maioria, possuem política ambiental estruturada, preocupam-se com o consumo consciente dos recursos naturais na abordagem de desempenho e no aspecto de cumprimento legal, e mostraram maior adequação às exigências legais devido aos novos processos ambientais angariados.

Participar do ISE é importante para as empresas por estarem em evidência de forma positiva. Contudo, faz-se necessário reconhecer se as informações inseridas nos questionários são àquelas divulgadas nos relatórios de sustentabilidade e, portanto, evidenciadas aos stakeholders em geral, minimizando a assimetria de informações. Deste modo, este estudo avança em relação à de Pletsch et al. (2014) por analisar as divergências e conformidades relacionadas aos indicadores dos 
anos de 2013 a 2016, tendo como proposta a seguinte questão de pesquisa: como as empresas que responderam o questionário ISE nos anos de 2013, 2014, 2015 e 2016, no aspecto ambiental, estão divulgando essas informações nos seus relatórios de sustentabilidade?

O objetivo desta pesquisa é identificar se as empresas estão respondendo o questionário ISE de acordo com suas ações refletidas nos relatórios de sustentabilidade publicados nos seus websites. É necessário que o meio ambiente possua uma maior importância dentro das organizações, de modo que as ações planejadas pela empresa sejam revistas. Esta pesquisa, ao identificar as principais diferenças entre o conteúdo do questionário e dos relatórios de sustentabilidade permitirá avaliar as empresas no que tange a fidedignidade das informações divulgadas aos seus usuários externos.

Para fins deste estudo, acredita-se que aprofundar as pesquisas em relação aos dados apresentados pelo ISE, pode ser uma boa fonte para o seu aprimoramento, visto que o mesmo está sempre sendo atualizado conforme sugestões e melhorias realizadas anualmente, além de demonstrar a atual situação da evidenciação ambiental.

\section{REFERENCIAL TEÓRICO}

\subsection{SUSTENTABILIDADE EMPRESARIAL E INDICADORES AMBIENTAIS}

O Índice de Sustentabilidade Empresarial (ISE) consiste em um índice de sustentabilidade nos moldes dos índices Dow Jones Sustainability Indexes (DJSI), FTSE4 Good Series e Johannesburg Stock Exchange SRI Index e tem como objetivo propiciar um ambiente de investimento compatível com as demandas de desenvolvimento sustentável da sociedade contemporânea e estimular a responsabilidade social corporativa, considerada por meio de aspectos de governança corporativa e sustentabilidade empresarial (eficiência econômica, equilíbrio ambiental e justiça social) (REZENDE et al., 2008).

O ISE mede o retorno total de uma carteira da BM\&FBOVESPA composta por ações de empresas com reconhecido comprometimento com a responsabilidade social e a sustentabilidade empresarial (SILVA et al., 2011) e está fundamentado em três aspectos: dar transparência ao processo e às respostas das empresas por meio do questionário; criar um diálogo e manter os canais de acesso entre as partes interessadas e a sociedade; atualizar anualmente o questionário ISE, com base em pesquisas acadêmicas e processos participativos, garantindo autonomia financeira, condições técnicas, materiais e de gestão para que o ISE tenha plena legitimidade e credibilidade necessária para cumprir seu papel em sua missão (BM\&FBOVESPA, 2016).

Székely e Knirsch (2005) verificaram que existem diversas abordagens utilizadas para medir, monitorar e avaliar o progresso da empresa em direção à sustentabilidade, tais como: índices de sustentabilidade, critérios de investidores, benchmarking, entre outros. Contudo, os autores observaram que nenhum desses métodos representa uma ferramenta universal clara que pode ser usada por todas as indústrias ou por todas as empresas da mesma indústria.

Desta forma, Silva et al. (2011) direcionaram sua pesquisa para as empresas do setor de energia elétrica. Os principais resultados mostraram que o alto grau de exigências impostas pelos órgãos reguladores do setor de energia elétrica e as determinações abordadas na governança corporativa, principalmente as relacionadas às ações ambientais, influenciam a predominância de empresas deste setor na composição do ISE, visto que o índice é composto por ações de empresas com reconhecido comprometimento com a responsabilidade social e sustentabilidade empresarial.

Feil e Naime (2015) apuraram a sustentabilidade nas corporações por meio do modelo de Grid de Sustentabilidade Empresarial (GSE). Este modelo contempla os aspectos ambientais, sociais e econômicos. De modo abrangente, os resultados apontam que as empresas que possuem 
o selo ISE não apresentam insustentabilidade, uma vez que da amostra estudada, 76,53\% situamse na pontuação adequada e os $23,47 \%$ restantes estão na direção adequada para o atingimento desta pontuação. As empresas que compõem o ISE apresentam menor desempenho na dimensão ambiental, estando primeiramente o aspecto social e depois o econômico. Porém, o score ambiental apresentou a maior média, identificando que as empresas se esforçam também para otimizar este quesito.

López, Garcia e Rodriguez (2007) examinaram se o desempenho do negócio é afetado pela adoção de práticas incluídas no termo Responsabilidade Social Corporativa (RSC). A análise empírica suporta a conclusão de que existem diferenças de desempenho entre as empresas que pertencem ao Índice Dow Jones de Sustentabilidade e ao Dow Jones Global Index e que essas diferenças estão relacionadas às práticas de RSC. Os autores acreditam que um impacto negativo a curto prazo no desempenho é produzido.

\subsection{DIVULGAÇÕES DE INFORMAÇÕES SOCIAIS E AMBIENTAIS}

O mercado acionário tem buscado aplicar seus fundos em alternativas que resultam na minimização de riscos e maximização do retorno aos acionistas e investidores de diferentes vertentes e objetivos dentro da organização. Para atender a este critério, têm-se por exemplo, os investimentos sociais que possuem aplicações diferenciadas para investidores do mercado acionário, assim como premia as empresas que trabalham com condutas de responsabilidade social, práticas de governança corporativa e desenvolvimento sustentável (REZENDE et al., 2008).

Para Rezende et al. (2008), esses investimentos em fundos de ações dessas empresas, estão relacionados ao plano estratégico competitivo de responsabilidade ambiental, ético e social e é considerado um novo segmento da indústria de fundos mútuos em renda variável, representando um segmento promissor em países como Japão, Estados Unidos e alguns países da Europa e América Latina.

Segundo Novelini e Fregonesi (2013) um dos problemas enfrentados pelas empresas que fornecem seus relatórios sociais, está na duplicação das informações sobre investimentos em projetos de forma consecutiva nos anos subsequentes ao início dos mesmos, sem que ocorra alterações nos dados apresentados ou esclarecimento da estagnação, comprovando a ineficiência na transparência das informações publicadas pelas empresas.

Neste sentido, Pletsch et al. (2014) concluíram que se tratando do requisito ambiental, no projeto de novos produtos (bens ou serviços), processos ou empreendimentos, 71,4\% das companhias estudadas justificaram ter uma prática plenamente implementada abrangendo todos os produtos. Em relação ao desenvolvimento e inovação tecnológica com vistas à melhoria de seu desempenho ambiental, 42,9\% das companhias indicaram ser uma prática sistemática da companhia, com dotação orçamentária e pessoal específica para esta finalidade e já produziu resultados concretos e mensuráveis no desempenho ambiental da companhia.

Em relação aos dados obtidos na pesquisa de Feil e Naime (2015), 76,53\% das corporações pertencentes ao ISE obtiveram sustentabilidade satisfatória, 17,65\% obtiveram sustentabilidade relativa e $8,82 \%$ obtiveram sustentabilidade fraca, concluindo com base nesses dados, que o ISE apresentava uma potencialidade de $76,53 \%$ para ser considerada sustentável. Os $23,47 \%$ restantes estavam a caminho da sustentabilidade corporativa. Dessa forma, nenhuma corporação com selo do ISE apresentou insustentabilidade. 


\section{METODOLOGIA DA PESQUISA}

Esta pesquisa tem caráter descritivo com abordagem qualitativa, e busca aprimorar a análise sobre evidenciação ambiental nas empresas participantes do Índice de Sustentabilidade Empresarial, assim como fizeram Pletsch et al. (2014) e Feil e Naime (2015).

A amostra constitui-se das 18 empresas do grupo A da carteira ISE, na dimensão ambiental que responderam e permitiram a divulgação dos questionários nos anos de 2013, 2014, 2015 e 2016. Apesar de as empresas passarem a permitir a divulgação do questionário em 2010, a adesão a esta proposta foi gradativa, e por este motivo optou-se em analisar o período mencionado, que reflete o panorama das empresas participantes do índice, especialmente para obter percepções na evolução da coerência das informações divulgadas nos relatórios de sustentabilidade e com aquelas fornecidas pelo ISE por meio do questionário. A seleção da amostra partiu da carteira de empresas que tiveram suas respostas divulgadas em um dos 4 (quatro) anos analisados.

Os questionários foram baixados no site da BM\&FBOVESPA e os relatórios de sustentabilidade nos sites de cada empresa. Depois dessas coletas, realizou-se o enquadramento e alinhamento das repostas em uma planilha de Excel onde evidenciou-se cada resposta em cada ano respectivo para cada empresa.

Em seguida, foi analisado o questionário individualmente, sendo avaliado se os relatórios apresentam a confirmação das respostas fornecidas, a fim de encontrar semelhanças e diferenças das informações divulgadas.

Os resultados foram apresentados por meio de percentual em tabelas que contêm os indicadores do questionário ISE, evidenciando se as respostas foram apresentadas de acordo com os relatórios; de forma divergente entre o questionário e o relatório de sustentabilidade; se a empresa não respondeu à pergunta (sendo que pode ter sido aplicada ou não no ano, dado que os questionários são atualizados no decorrer do tempo); e se a empresa não apresentou o relatório em seu website naquele ano. O Quadro 1 apresenta a codificação das análises conforme as respostas das empresas e suas respectivas anuências no relatório de sustentabilidade e similares.

\section{Quadro 1 - Codificação das análises}

\begin{tabular}{|l|l|}
\hline DA & Respostas de acordo com o relatório de sustentabilidade e similares \\
\hline DV & Respostas divergentes do relatório de sustentabilidade e similares \\
\hline NR & Empresa não respondeu à pergunta \\
\hline SR & Empresa não apresentou o relatório em seu website \\
\hline
\end{tabular}

Fonte: Elaborado pelas autoras (2017).

Para coleta e análise da pesquisa, foi realizada uma padronização dos questionários ISE analisados, uma vez que os questionários ISE de 2015 e 2016 trouxeram mais perguntas que os demais anos. Desta forma, utilizou-se como padrão os indicadores estabelecidos no questionário de 2013, acrescentando as perguntas incluídas nos anos de 2015 e 2016. Com esta análise concluída, foi possível responder a problemática desta pesquisa, observando cada informação obtida.

Os itens abordados no questionário referentes a temática ambiental da carteira ISE são divididos em Critérios e Indicadores. O Critério I trata-se da Política dentro da organização e seu indicador refere-se ao compromisso, abrangência e divulgação. O Critério II (Gestão) é composto de 2 (dois) indicadores. O Indicador 2 diz respeito à responsabilidade ambiental e o Indicador 3, ao planejamento. O Critério III está voltado para o desempenho e é formado por 8 (oito) indicadores, sendo: Indicador 4: gerenciamento e monitoramento; Indicador 5: certificações; 
Indicador 6: comunicação com partes interessadas; Indicador 7: compromisso global biodiversidade; Indicador 8: consumo de recursos ambientais - inputs; Indicador 9: emissões atmosféricas, efluentes líquidos e resíduos; Indicador 10: emissões e resíduos críticos e Indicador 11: seguro ambiental. Por fim, foi verificado o critério IV sobre o cumprimento legal. Neste critério há 4 (quatro) indicadores: Indicador 12: área de preservação permanente; Indicador 13: reserva legal; Indicador 14: passivos ambientais e Indicador 15: requisitos administrativos.

As empresas que autorizaram e tiveram suas respostas divulgadas na carteira ISE e compuseram a amostra deste trabalho, podem ser observadas no Quadro 2.

Quadro 1 - Empresas que autorizaram suas publicações na Carteira ISE

\begin{tabular}{|c|c|c|c|c|}
\hline Qtd & 2013 & 2014 & 2015 & 2016 \\
\hline 1 & Aes Tiete S.A. & Aes Tiete S.A. & Aes Tiete S.A. & Aes Tiete S.A. \\
\hline 2 & Eletronorte & Eletronorte & Eletronorte & Eletronorte \\
\hline 3 & CHESF & CHESF & CHESF & CHESF \\
\hline 4 & $\begin{array}{l}\text { Cia de Geração Térm. } \\
\text { de Energia Elétrica }\end{array}$ & $\begin{array}{l}\text { Cia de Geração Térm. } \\
\text { de Energia Elétrica }\end{array}$ & $\begin{array}{l}\text { Cia de Geração Térm. } \\
\text { de Energia Elétrica }\end{array}$ & $\begin{array}{l}\text { Cia de Geração Térm. de } \\
\text { Energia Elétrica }\end{array}$ \\
\hline 5 & $\begin{array}{l}\text { Eletrobrás } \\
\text { Termonuclear S.A. }\end{array}$ & $\begin{array}{l}\text { Eletrobrás } \\
\text { Termonuclear S.A. }\end{array}$ & $\begin{array}{l}\text { Eletrobrás } \\
\text { Termonuclear S.A. }\end{array}$ & $\begin{array}{l}\text { Eletrobrás Termonuclear } \\
\text { S.A. }\end{array}$ \\
\hline 6 & $\begin{array}{l}\text { Eletrosul Centrais } \\
\text { Elétricas S.A. }\end{array}$ & $\begin{array}{l}\text { Eletrosul Centrais } \\
\text { Elétricas S.A. }\end{array}$ & $\begin{array}{l}\text { Eletrosul Centrais } \\
\text { Elétricas S.A. }\end{array}$ & $\begin{array}{l}\text { Eletrosul Centrais Elétricas } \\
\text { S.A. }\end{array}$ \\
\hline 7 & $\begin{array}{l}\text { Furnas Centrais } \\
\text { Elétricas S.A. }\end{array}$ & $\begin{array}{l}\text { Furnas Centrais } \\
\text { Elétricas S.A. }\end{array}$ & $\begin{array}{l}\text { Furnas Centrais } \\
\text { Elétricas S.A. }\end{array}$ & $\begin{array}{l}\text { Furnas Centrais Elétricas } \\
\text { S.A. }\end{array}$ \\
\hline 8 & Itaipu Binacional & Itaipu Binacional & Itaipu Binacional & Itaipu Binacional \\
\hline 9 & $\begin{array}{l}\text { Cemig Geração e } \\
\text { Transmissão S.A. }\end{array}$ & $\begin{array}{l}\text { Cemig Geração e } \\
\text { Transmissão S.A. }\end{array}$ & $\begin{array}{l}\text { Cemig Geração e } \\
\text { Transmissão S.A. }\end{array}$ & $\begin{array}{l}\text { Cemig Geração e } \\
\text { Transmissão S.A. }\end{array}$ \\
\hline 10 & $\begin{array}{l}\text { Copel Geração e } \\
\text { Transmissão S.A. }\end{array}$ & $\begin{array}{l}\text { Copel Geração e } \\
\text { Transmissão S.A. }\end{array}$ & $\begin{array}{l}\text { Copel Geração e } \\
\text { Transmissão S.A. }\end{array}$ & $\begin{array}{l}\text { Copel Geração e } \\
\text { Transmissão S.A. }\end{array}$ \\
\hline 11 & COPASA MG* & $\begin{array}{l}\text { CPFL Geração de } \\
\text { Energia S.A. }\end{array}$ & $\begin{array}{l}\text { CPFL Geração de } \\
\text { Energia S.A. }\end{array}$ & $\begin{array}{l}\text { Porto do Pecém Geração de } \\
\text { Energia S.A. }\end{array}$ \\
\hline 12 & Duratex S.A.* & $\begin{array}{l}\text { Engie Brasil Energia } \\
\text { S.A. }\end{array}$ & $\begin{array}{l}\text { Engie Brasil Energia } \\
\text { S.A. }\end{array}$ & Engie Brasil Energia S.A. \\
\hline 13 & Enerpeixe S.A.* & Fibria Celulose S.A. & Fibria Celulose S.A. & Fibria Celulose S.A. \\
\hline 14 & Klabin S.A. & Klabin S.A. & Klabin S.A. & Klabin S.A. \\
\hline
\end{tabular}

*Empresas que não divulgaram suas respostas em 2014, 2015 e 2016

**Empresa que não divulgaram suas respostas em 2016

Fonte: BM\&FBOVESPA (2016)

\section{APRESENTAÇÃO E DISCUSSÃO DOS RESULTADOS}

Um dos pilares que sustenta os itens que determinam as empresas que compõem o ISE e que, portanto, são reconhecidas por esta metodologia como as mais sustentáveis, são as respostas dos questionários ISE. Nesta seção serão apresentados os indicadores sugeridos nos questionários ISE em tabelas, apresentando nas linhas as perguntas e nas colunas as respostas dos anos. A porcentagem significa a comparação dessas respostas com o relatório de sustentabilidade, de modo a serem verificadas se as informações estavam em ambos os documentos e na mesma direção. Foi necessário realizar a abreviação para as colunas das tabelas, onde DA significa que as respostas 
estão de acordo com os relatórios; DV significa que as respostas estão divergentes com seus relatórios; NR significa que a empresa não respondeu à pergunta e SR significa que a empresa não apresentou o relatório em seu website no ano respectivo. A Tabela 1 apresenta o Indicador 1 Compromisso, Abrangência e Divulgação.

Tabela 1 - Indicador 1 - Compromisso, Abrangência e Divulgação

\begin{tabular}{|c|c|c|c|c|c|c|c|c|c|c|c|c|c|}
\hline \multirow{2}{*}{ PERGUNTA } & \multicolumn{3}{|c|}{2013} & \multicolumn{3}{|c|}{2014} & \multicolumn{3}{|c|}{2015} & \multicolumn{4}{|c|}{2016} \\
\hline & DA & DV & NR & DA & DV & NR & DA & DV & NR & DA & DV & NR & SR \\
\hline $\begin{array}{l}\text { 1. A companhia possui uma política } \\
\text { ambiental cujas diretrizes são } \\
\text { refletidas nos seus processos de } \\
\text { planejamento e gestão? }\end{array}$ & $100 \%$ & $0 \%$ & $0 \%$ & $83 \%$ & $0 \%$ & $17 \%$ & $83 \%$ & $0 \%$ & $17 \%$ & $39 \%$ & $0 \%$ & $22 \%$ & $39 \%$ \\
\hline $\begin{array}{l}\text { 1.1. Se SIM para a PERGUNTA } 1 \text {, } \\
\text { quais mecanismos são utilizados para } \\
\text { verificação do nível de conhecimento } \\
\text { e comprometimento do público } \\
\text { interno em relação à política } \\
\text { ambiental }\end{array}$ & $100 \%$ & $0 \%$ & $0 \%$ & $83 \%$ & $0 \%$ & $17 \%$ & $83 \%$ & $0 \%$ & $17 \%$ & $39 \%$ & $0 \%$ & $22 \%$ & $39 \%$ \\
\hline
\end{tabular}

Fonte: Dados da pesquisa (2017).

Como observado na Tabela 1, nenhuma das empresas apresentaram divergência em relação às políticas ambientais adotadas. Esse resultado corrobora o estudo de Pletsch et al. (2014), uma vez que a maioria das empresas que os autores analisaram declararam possuir política ambiental estruturada e demonstraram cumprir os compromissos assumidos.

No entanto, nota-se que os cenários mudaram de 2013 para 2016, ocasionados pela mudança das empresas que permitiram a divulgação das respostas dos questionários ou sobre o próprio entendimento das reações da política ambiental na empresa. A tendência é que as políticas sejam aperfeiçoadas e a aplicação nos processos pode ser mais eficiente ou não, a depender da estrutura da companhia e os recursos disponibilizados. Em 2016, esta pergunta em $22 \%$ dos casos não foi respondida e 39\% não apresentaram relatório de sustentabilidade. Cabe a reflexão sobre a importância da política ambiental no decorrer do tempo para a empresa e quais os incentivos necessários para que ela se torne mecanismo fundamental e constante. Aponta-se ainda que em 2016, o percentual de empresas que não apresentaram o relatório de sustentabilidade foi significativo, apesar de a maior parte das empresas pertencer ao segmento de energia elétrica que é setor regulado, que de modo geral, devido a legislação específica, tende a possuir maior disclosure de informações.

De modo geral, nos relatórios de sustentabilidade as empresas divulgam de forma contundente que as políticas adotadas não estão preocupadas apenas com os requisitos ambientais, conforme trecho apresentado pela Eletrobrás (2015, p.43): "Esses princípios refletem não só a preocupação com o atendimento aos requisitos de sustentabilidade necessários para a atuação da empresa, como também a busca constante das melhores práticas no relacionamento com os públicos de interesse". A Tabela 2 apresenta o Indicador 2 - Responsabilidade Ambiental. 
Tabela 2 -Indicador 2 - Responsabilidade Ambiental

\begin{tabular}{|c|c|c|c|c|c|c|c|c|c|c|c|c|c|}
\hline \multirow{2}{*}{ PERGUNTA } & \multicolumn{3}{|c|}{2013} & \multicolumn{3}{|c|}{2014} & \multicolumn{3}{|c|}{2015} & \multicolumn{4}{|c|}{2016} \\
\hline & DA & DV & NR & DA & DV & NR & DA & DV & NR & DA & DV & NR & SR \\
\hline $\begin{array}{l}\text { 2. A companhia possui uma } \\
\text { política corporativa que contemple } \\
\text { aspectos de Saúde e Segurança no } \\
\text { Trabalho (SST) cujas diretrizes } \\
\text { são refletidas nos seus processos } \\
\text { de planejamento e gestão? }\end{array}$ & $100 \%$ & $0 \%$ & $0 \%$ & $67 \%$ & $16 \%$ & $17 \%$ & $83 \%$ & $0 \%$ & $17 \%$ & $39 \%$ & $0 \%$ & $22 \%$ & $39 \%$ \\
\hline $\begin{array}{l}\text { 2.1 Se SIM para a PERGUNTA 2, } \\
\text { quais mecanismos são utilizados } \\
\text { para verificação do nível de } \\
\text { conhecimento e comprometimento } \\
\text { do público interno em relação à } \\
\text { política corporativa que contemple } \\
\text { aspectos de Saúde e Segurança no } \\
\text { Trabalho (SST)? }\end{array}$ & $100 \%$ & $0 \%$ & $0 \%$ & $78 \%$ & $5 \%$ & $17 \%$ & $78 \%$ & $5 \%$ & $17 \%$ & $39 \%$ & $0 \%$ & $22 \%$ & $39 \%$ \\
\hline $\begin{array}{l}\text { 2. Indique para quais níveis } \\
\text { hierárquicos da companhia há } \\
\text { atribuições ambientais específicas } \\
\text { na descrição formal das funções } \\
\text { (descrição de cargo): }\end{array}$ & $100 \%$ & $0 \%$ & $0 \%$ & $83 \%$ & $0 \%$ & $17 \%$ & $83 \%$ & $0 \%$ & $17 \%$ & $39 \%$ & $0 \%$ & $22 \%$ & $39 \%$ \\
\hline $\begin{array}{l}\text { 3. O principal gestor ambiental da } \\
\text { companhia responde diretamente a } \\
\text { qual nível hierárquico? }\end{array}$ & $17 \%$ & $83 \%$ & $0 \%$ & $16 \%$ & $67 \%$ & $17 \%$ & $67 \%$ & $16 \%$ & $17 \%$ & $39 \%$ & $5 \%$ & $17 \%$ & $39 \%$ \\
\hline
\end{tabular}

Legenda: DA: de acordo; DV: divergente; NR: não respondeu; SR: sem relatório.

Fonte: Dados da pesquisa (2017).

As normas de segurança do trabalho são regulamentadas e nota-se nos percentuais apresentados, uma maior preocupação das companhias em efetivamente realizar e apresentar as ações que contemplem estas normas. Progresso ocorreu especialmente no item 3 sobre identificar a qual nível hierárquico responde o principal gestor ambiental, que em 2013 apresentava $83 \%$ de divergência e 2016, 5\%. Tal percentual pode estar relacionado com maior alinhamento de um setor de sustentabilidade na empresa, assim como a união com a área de segurança do trabalho que é imposta por legislação do Ministério do Trabalho e Emprego (MTE).

Observa-se que em 2013 há um equilíbrio entre as respostas do questionário e o relatório apresentado, o que não ocorre nos outros anos onde as divergências são acentuadas. O motivo pode estar relacionado com a descentralização das atividades dentro da companhia, onde cada setor veicula informações sem que elas sejam cruzadas para verificar discrepâncias. Por exemplo, o indivíduo responsável por responder o questionário ISE, não é o mesmo que elabora o relatório de sustentabilidade. A empresa AES TIETE (2014, p.29) em seu relatório de sustentabilidade descreve o seguinte sobre os aspectos de governança: "A estrutura de gestão das empresas do Grupo AES Brasil é descentralizada e se apoia no relacionamento entre acionistas, administradores, auditores independentes e conselho fiscal para alinhamento de políticas e decisões corporativas". A Tabela 3 apresenta o Indicador 3 - Planejamento. 
Tabela 3 - Indicador 3 - Planejamento

\begin{tabular}{|c|c|c|c|c|c|c|c|c|c|c|c|c|c|}
\hline \multirow{2}{*}{ PERGUNTA } & \multicolumn{3}{|c|}{2013} & \multicolumn{3}{|c|}{2014} & \multicolumn{3}{|c|}{2015} & \multicolumn{4}{|c|}{2016} \\
\hline & DA & DV & NR & DA & DV & NR & DA & DV & NR & DA & DV & NR & SR \\
\hline $\begin{array}{l}\text { 4. Qual a situação da companhia em } \\
\text { relação a avaliação ambiental } \\
\text { periódica de seus aspectos e } \\
\text { impactos ambientais? }\end{array}$ & $100 \%$ & $0 \%$ & $0 \%$ & $83 \%$ & $0 \%$ & $17 \%$ & $83 \%$ & $0 \%$ & $17 \%$ & $39 \%$ & $0 \%$ & $22 \%$ & $39 \%$ \\
\hline $\begin{array}{l}\text { 5. Qual a abordagem utilizada pela } \\
\text { companhia para a avaliação de seu } \\
\text { desempenho ambiental? }\end{array}$ & $100 \%$ & $0 \%$ & $0 \%$ & $83 \%$ & $0 \%$ & $17 \%$ & $83 \%$ & $0 \%$ & $17 \%$ & $39 \%$ & $0 \%$ & $22 \%$ & $39 \%$ \\
\hline $\begin{array}{l}5 \text { A companhia avalia os riscos e } \\
\text { oportunidades derivados da relação } \\
\text { de suas operações com os serviços } \\
\text { ecossistêmicos? }\end{array}$ & $0 \%$ & $0 \%$ & $0 \%$ & $0 \%$ & $0 \%$ & $0 \%$ & $78 \%$ & $6 \%$ & $17 \%$ & $44 \%$ & $0 \%$ & $17 \%$ & $39 \%$ \\
\hline $\begin{array}{l}\text { 6. Qual a situação da companhia em } \\
\text { relação à incorporação de requisitos } \\
\text { ambientais no projeto de novos } \\
\text { produtos (bens ou serviços), } \\
\text { processos ou empreendimentos? }\end{array}$ & $100 \%$ & $0 \%$ & $0 \%$ & $83 \%$ & $0 \%$ & $17 \%$ & $0 \%$ & $0 \%$ & $0 \%$ & $0 \%$ & $0 \%$ & $0 \%$ & $0 \%$ \\
\hline $\begin{array}{l}\text { 7. Qual a situação da companhia em } \\
\text { relação à pesquisa, } \\
\text { desenvolvimento e inovação } \\
\text { tecnológica com vistas a melhoria } \\
\text { de seu desempenho ambiental? }\end{array}$ & $100 \%$ & $0 \%$ & $0 \%$ & $83 \%$ & $0 \%$ & $17 \%$ & $83 \%$ & $0 \%$ & $17 \%$ & $39 \%$ & $0 \%$ & $22 \%$ & $39 \%$ \\
\hline $\begin{array}{l}\text { 8. Indique o percentual das } \\
\text { unidades da companhia nas quais as } \\
\text { práticas de gestão de saúde e } \\
\text { segurança no trabalho (SST) estão } \\
\text { plenamente implementadas }\end{array}$ & $100 \%$ & $0 \%$ & $0 \%$ & $83 \%$ & $0 \%$ & $17 \%$ & $83 \%$ & $0 \%$ & $17 \%$ & $39 \%$ & $0 \%$ & $22 \%$ & $39 \%$ \\
\hline $\begin{array}{l}\text { 9. Assinale as situações para as } \\
\text { quais os processos de gestão da } \\
\text { companhia incorporam o uso } \\
\text { sustentável dos recursos naturais } \\
\text { renováveis como requisito } \\
\text { prioritário? }\end{array}$ & $100 \%$ & $0 \%$ & $0 \%$ & $83 \%$ & $0 \%$ & $17 \%$ & $83 \%$ & $0 \%$ & $17 \%$ & $39 \%$ & $0 \%$ & $22 \%$ & $39 \%$ \\
\hline
\end{tabular}

Fonte: Dados da pesquisa (2017.

Observa-se que $100 \%$ das empresas que responderam os questionários ISE nos anos de 2013 estão coerentes com os relatórios no tocante aos aspectos do desempenho ambiental e seu planejamento. Em 2014 e 2015, o percentual de consonância foi de 83\%, baixando para 39\% em 2016. Em 2015 a questão de número 5 (cinco) apresentou 6\% de divergência, que se refere a empresa que respondeu não realizar a avaliação de riscos de forma explicita em seu relatório, que identifica a necessidade de maior troca de informação entre os gestores e responsáveis pela elaboração dos relatórios e a resposta ao ISE. Na Tabela 4 é apresentado o Indicador 4 Gerenciamento e Monitoramento. 
Tabela 4 - Indicador 4 - Gerenciamento e Monitoramento

\begin{tabular}{|c|c|c|c|c|c|c|c|c|c|c|c|c|c|}
\hline \multirow{2}{*}{ PERGUNTA } & \multicolumn{3}{|c|}{2013} & \multicolumn{3}{|c|}{2014} & \multicolumn{3}{|c|}{2015} & \multicolumn{4}{|c|}{2016} \\
\hline & DA & DV & NR & DA & DV & NR & DA & DV & NR & DA & DV & NR & SR \\
\hline $\begin{array}{l}\text { 10. Indique o percentual dos } \\
\text { processos e atividades da } \\
\text { companhia (PPA), considerados } \\
\text { potencial ou efetivamente } \\
\text { geradores de impactos ambientais } \\
\text { significativos, que é orientado por } \\
\text { procedimentos operacionais } \\
\text { específicos: }\end{array}$ & $100 \%$ & $0 \%$ & $0 \%$ & $83 \%$ & $0 \%$ & $17 \%$ & $83 \%$ & $0 \%$ & $17 \%$ & $39 \%$ & $0 \%$ & $22 \%$ & $39 \%$ \\
\hline $\begin{array}{l}\text { 11. Indique as práticas da } \\
\text { companhia relacionadas à melhoria } \\
\text { do desempenho ambiental na } \\
\text { cadeia de suprimentos: }\end{array}$ & $100 \%$ & $0 \%$ & $0 \%$ & $83 \%$ & $0 \%$ & $17 \%$ & $83 \%$ & $0 \%$ & $17 \%$ & $39 \%$ & $0 \%$ & $22 \%$ & $39 \%$ \\
\hline $\begin{array}{l}\text { 12. Quais as ações da companhia } \\
\text { em relação ao consumo/uso } \\
\text { sustentável de seus } \\
\text { produtos/serviços? }\end{array}$ & $100 \%$ & $0 \%$ & $0 \%$ & $61 \%$ & $22 \%$ & $17 \%$ & $83 \%$ & $0 \%$ & $17 \%$ & $39 \%$ & $0 \%$ & $22 \%$ & $39 \%$ \\
\hline
\end{tabular}
Fonte: Dados da pesquisa (2017).

Os indicadores de gerenciamento e monitoramento mostram que $100 \%$ das empresas apresentaram consonância entre as respostas dos questionários ISE e os relatórios em 2013, já em 2014 e 2015 o percentual caiu para 83\%, seguindo para 39\% no ano de 2016. Em 2014, na questão de número 12 (doze) 22\% das empresas estão divergentes, pois responderam não ter ações em relação ao consumo/uso sustentável de seus produtos/serviços, porém em seus relatórios apresentam tais ações. A Tabela 5 apresenta o Indicador 5 - Certificações.

Quanto às certificações, tal achado vai ao encontro do estudo desenvolvido por Pletsch et al. (2014), em que mais da metade das entidades possui sistema de gestão ambiental.

A Tabela 5 demonstra que as empresas estão em sintonia no que diz respeito às certificações dentro das organizações nos 4 (quatro) anos analisados. Apesar dos percentuais apresentarem a conformidade entre as respostas, sim ou não, entre o questionário e o relatório de sustentabilidade, vale lembrar que nem todas as empresas utilizam as certificações mencionadas, uma vez que algumas delas são destinadas a atividades específicas. No ano de 2016 não houve nenhuma empresa com divergência, contudo este ano se difere dos demais já que 39\% das empresas não apresentaram relatório de sustentabilidade em seu website. 
Tabela 5 - Indicador 5 - Certificações

\begin{tabular}{|c|c|c|c|c|c|c|c|c|c|c|c|c|c|}
\hline \multirow{2}{*}{ PERGUNTA } & \multicolumn{3}{|c|}{2013} & \multicolumn{3}{|c|}{2014} & \multicolumn{3}{|c|}{2015} & \multicolumn{4}{|c|}{2016} \\
\hline & DA & DV & NR & DA & DV & NR & DA & DV & NR & DA & DV & NR & SR \\
\hline $\begin{array}{l}\text { 13. A companhia possui } \\
\text { sistemas de gestão (ambiental; } \\
\text { de saúde e segurança do } \\
\text { trabalhador, responsabilidade } \\
\text { social ou florestal) certificados } \\
\text { por Organismo Certificador } \\
\text { Acreditado (OCA)? }\end{array}$ & $94 \%$ & $6 \%$ & $0 \%$ & $78 \%$ & $6 \%$ & $17 \%$ & $83 \%$ & $0 \%$ & $17 \%$ & $39 \%$ & $0 \%$ & $22 \%$ & $39 \%$ \\
\hline $\begin{array}{l}\text { 13.1. Se SIM para a } \\
\text { PERGUNTA 13, indique o } \\
\text { percentual (\%) da } \\
\text { produção/serviços (em unidade } \\
\text { de medida pertinente) cobertos } \\
\text { por sistemas de gestão } \\
\text { (ambiental; de saúde e } \\
\text { segurança do trabalhador ou } \\
\text { responsabilidade social), } \\
\text { certificados por Organismo } \\
\text { Certificador Acreditado (OCA): }\end{array}$ & $72 \%$ & $0 \%$ & $28 \%$ & $56 \%$ & $17 \%$ & $28 \%$ & $56 \%$ & $17 \%$ & $28 \%$ & $33 \%$ & $0 \%$ & $28 \%$ & $39 \%$ \\
\hline $\begin{array}{l}\text { 13.2. Se SIM para a } \\
\text { PERGUNTA 13, indique o } \\
\text { percentual (\%) da } \\
\text { produção/serviços (em unidade } \\
\text { de medida pertinente) cobertos } \\
\text { por sistemas de gestão com } \\
\text { certificação florestal emitida por } \\
\text { Organismo Certificador } \\
\text { Acreditado (OCA): }\end{array}$ & $72 \%$ & $0 \%$ & $28 \%$ & $56 \%$ & $0 \%$ & $44 \%$ & $61 \%$ & $0 \%$ & $39 \%$ & $33 \%$ & $0 \%$ & $28 \%$ & $39 \%$ \\
\hline
\end{tabular}
Fonte: Dados da pesquisa (2017).

O item 13, no ano de 2013 e 2014 apresentou 6\% de divergência, uma vez que as empresas responderam não possuir certificações no questionário e o inverso em seus relatórios de sustentabilidade. Em 2014 e 2015, 17\% das empresas responderam de forma divergente a questão 13.1 (treze ponto um), pois apresentaram em seus relatórios valores diferentes das respostas do questionário. Em relação à pergunta 13 (treze) uma das empresas indicou no seu relatório divergência com a resposta sendo que no relatório apresentava nível menor que $40 \%$ em todos os aspectos, mesmo assim sua resposta estava em conformidade com o questionário ISE: "a) Sistema de gestão ambiental - 100\%; b) Sistema de gestão de saúde e segurança do trabalhador - 100\% e c) Sistema de gestão de responsabilidade social - $>0 \%$ e $\leq 40 \%$ ", isto pode ser justificado pela forma como o responsável por responder esta questão identifica a empresa, diferente da forma como o responsável por elaborar o relatório de sustentabilidade. A Tabela 6 mostra o Indicador 6 - Comunicação com partes interessadas. 
Tabela 6 - Indicador 6 - Comunicação com partes interessadas

\begin{tabular}{|c|c|c|c|c|c|c|c|c|c|c|c|c|c|}
\hline \multirow{2}{*}{ PERGUNTA } & \multicolumn{3}{|c|}{2013} & \multicolumn{3}{|c|}{2014} & \multicolumn{3}{|c|}{2015} & \multicolumn{4}{|c|}{2016} \\
\hline & DA & DV & NR & DA & DV & NR & DA & DV & NR & DA & DV & NR & SR \\
\hline $\begin{array}{l}\text { 14. Indique a situação da companhia } \\
\text { quanto à comunicação com partes } \\
\text { interessadas em relação ao meio } \\
\text { ambiente e saúde e segurança no } \\
\text { trabalho: }\end{array}$ & $100 \%$ & $0 \%$ & $0 \%$ & $83 \%$ & $0 \%$ & $17 \%$ & $78 \%$ & $0 \%$ & $22 \%$ & $61 \%$ & $0 \%$ & $0 \%$ & $39 \%$ \\
\hline
\end{tabular}

Fonte: Dados da pesquisa (2017)

Na Tabela 6, a maioria das empresas apresentou suas respostas em concordância com seus relatórios, 100\%, 83\%, 78\% e 61\% nos anos de 2013, 2014, 2015 e 2016 respectivamente. Não houve nenhuma divergência em relação ao aspecto de comunicação entre as partes envolvidas, reafirmando de forma positiva a problemática deste estudo, onde este indicador fornece de forma clara e transparente a consonância entre a governança corporativa e seus interessados. Em 2014 17\% não responderam o questionário, em 2015 22\% e em 2016 nenhuma empresa deixou de responder o questionário.

A Tabela 7 apresenta o Indicador 7 - Compromisso Global: Biodiversidade.

Tabela 7 - Indicador 7: Compromisso Global - Biodiversidade

\begin{tabular}{|c|c|c|c|c|c|c|c|c|c|c|c|c|c|}
\hline \multirow{2}{*}{ PERGUNTA } & \multicolumn{3}{|c|}{2013} & \multicolumn{3}{|c|}{2014} & \multicolumn{3}{|c|}{2015} & \multicolumn{4}{|c|}{2016} \\
\hline & DA & DV & NR & DA & DV & NR & DA & DV & NR & DA & DV & NR & SR \\
\hline $\begin{array}{l}\text { 15. Selecione a alternativa que } \\
\text { descreve a situação da companhia } \\
\text { com relação aos impactos de suas } \\
\text { atividades, produtos ou serviços } \\
\text { sobre a biodiversidade: }\end{array}$ & $100 \%$ & $0 \%$ & $0 \%$ & $83 \%$ & $0 \%$ & $17 \%$ & $83 \%$ & $0 \%$ & $17 \%$ & $39 \%$ & $0 \%$ & $22 \%$ & $39 \%$ \\
\hline $\begin{array}{l}\text { 16. Indique quais as ações } \\
\text { desenvolvidas pela companhia em } \\
\text { prol da conservação e uso racional } \\
\text { dos recursos da biodiversidade? }\end{array}$ & $94 \%$ & $6 \%$ & $0 \%$ & $78 \%$ & $6 \%$ & $17 \%$ & $78 \%$ & $6 \%$ & $17 \%$ & $39 \%$ & $0 \%$ & $22 \%$ & $39 \%$ \\
\hline
\end{tabular}

Fonte: Dados da pesquisa (2017).

Exceto por 2016, ano atípico sobre a apresentação dos relatórios de sustentabilidade, percebe-se o empenho das empresas em evidenciar os impactos provocados pelas empresas e as soluções encontradas para minimizar tal situação, ou mesmo quando não o faz, permite que esta informação seja divulgada de forma simultânea no questionário ISE e no relatório de sustentabilidade, em quase $100 \%$ dos casos. Nas situações divergentes encontrou-se a seguinte situação: no questionário fora respondido que havia ações desenvolvidas pela companhia em prol da conservação e uso racional dos recursos da biodiversidade, enquanto que no relatório foi apontado o contrário. De modo geral, o nível de empresas "de acordo", supre e permite apresentar eficiência para o compromisso global.

A Tabela 8 apresenta o Indicador 8 - Consumo de Recursos Ambientais - Input. 
Tabela 8 - Indicador 8 - Consumo de Recursos Ambientais - Inputs

\begin{tabular}{|c|c|c|c|c|c|c|c|c|c|c|c|c|c|}
\hline \multirow{2}{*}{ PERGUNTA } & \multicolumn{3}{|c|}{2013} & \multicolumn{3}{|c|}{2014} & \multicolumn{3}{|c|}{2015} & \multicolumn{4}{|c|}{2016} \\
\hline & DA & DV & NR & DA & DV & NR & DA & DV & NR & DA & DV & NR & SR \\
\hline $\begin{array}{l}\text { 17. Qual a referência } \\
\text { mínima de desempenho } \\
\text { ambiental da } \\
\text { companhia? }\end{array}$ & $100 \%$ & $0 \%$ & $0 \%$ & $83 \%$ & $0 \%$ & $17 \%$ & $83 \%$ & $0 \%$ & $17 \%$ & $39 \%$ & $0 \%$ & $22 \%$ & $39 \%$ \\
\hline $\begin{array}{l}\text { 18. Qual a referência } \\
\text { mínima para o } \\
\text { desempenho da } \\
\text { companhia em saúde e } \\
\text { segurança no trabalho? }\end{array}$ & $100 \%$ & $0 \%$ & $0 \%$ & $83 \%$ & $0 \%$ & $17 \%$ & $83 \%$ & $0 \%$ & $17 \%$ & $39 \%$ & $0 \%$ & $22 \%$ & $39 \%$ \\
\hline $\begin{array}{l}\text { 19. O uso de recursos } \\
\text { naturais renováveis pela } \\
\text { organização gera, ou } \\
\text { gerou nos últimos } 10 \\
\text { anos, conflitos ou } \\
\text { restrição de uso destes } \\
\text { pela comunidade local? }\end{array}$ & $100 \%$ & $0 \%$ & $0 \%$ & $83 \%$ & $0 \%$ & $17 \%$ & $83 \%$ & $0 \%$ & $17 \%$ & $39 \%$ & $0 \%$ & $22 \%$ & $39 \%$ \\
\hline $\begin{array}{l}\text { 20. Com relação aos } \\
\text { processos produtivos da } \\
\text { companhia, selecione } \\
\text { cada opção caso a ação } \\
\text { indicada seja uma } \\
\text { prática na gestão dos } \\
\text { recursos naturais e } \\
\text { energéticos: }\end{array}$ & $100 \%$ & $0 \%$ & $0 \%$ & $83 \%$ & $0 \%$ & $17 \%$ & $83 \%$ & $0 \%$ & $17 \%$ & $39 \%$ & $0 \%$ & $22 \%$ & $39 \%$ \\
\hline $\begin{array}{l}\text { 21. Com relação aos } \\
\text { processos } \\
\text { administrativos da } \\
\text { companhia, selecione } \\
\text { cada opção caso a ação } \\
\text { indicada seja uma } \\
\text { prática na gestão do } \\
\text { recurso ambiental: }\end{array}$ & $100 \%$ & $0 \%$ & $0 \%$ & $83 \%$ & $0 \%$ & $17 \%$ & $83 \%$ & $0 \%$ & $17 \%$ & $39 \%$ & $0 \%$ & $22 \%$ & $39 \%$ \\
\hline $\begin{array}{l}\text { 22. Assinale o } \\
\text { percentual de reuso da } \\
\text { água nos processos } \\
\text { administrativos } \\
\text { (escritórios, refeitórios, } \\
\text { banheiros): }\end{array}$ & $72 \%$ & $28 \%$ & $0 \%$ & $56 \%$ & $28 \%$ & $17 \%$ & $56 \%$ & $28 \%$ & $17 \%$ & $33 \%$ & $6 \%$ & $22 \%$ & $39 \%$ \\
\hline $\begin{array}{l}23 \text { Qual o percentual } \\
\text { das instalações } \\
\text { dedicadas a processos } \\
\text { administrativos que } \\
\text { utilizam tecnologias de } \\
\text { uso eficiente de água? }\end{array}$ & $50 \%$ & $50 \%$ & $0 \%$ & $50 \%$ & $33 \%$ & $17 \%$ & $50 \%$ & $33 \%$ & $17 \%$ & $22 \%$ & $17 \%$ & $22 \%$ & $39 \%$ \\
\hline
\end{tabular}

Fonte: Dados da pesquisa (2017)

Conforme a Tabela 8, observa-se que nos 4 (quatro) anos ocorreu grande número de divergência entre os aspectos estabelecidos nas perguntas 22 e 23, pertinente ao reuso de recursos hídricos nos processos administrativos e o percentual utilizado respectivamente. Muitas empresas 
responderam não ter o reuso e em seus relatórios apresentarem até mesmo projetos de reuso dentro da organização. O percentual em consonância com os relatórios teve $100 \%$ de aderência no ano de 2013, nas primeiras respostas. Em 2014 e 2015 tiveram o mesmo percentual de conformidade para as primeiras respostas, $83 \%$ estão acordadas.

Dentro desta lógica, entre os $33 \%$ das empresas que responderam de forma divergente, a empresa Itaipu (2015, p. 44-50), apresentou como resposta à pergunta de número 23 ter menor ou igual a $20 \%$ de instalações dedicadas a processos administrativos que utilizam tecnologias de uso eficiente de água, já no seu relatório de sustentabilidade do mesmo ano apresentou ter recebido o "Prêmio Water for Life" de melhores práticas em gestão da água da 5 a edição do Prêmio Água para a Vida, promovido pela ONU Água.

A Tabela 9 apresenta o Indicador 9 - Emissões atmosféricas, Efluentes Líquidos e Resíduos.

\section{Tabela 9 - Indicador 9 - Emissões atmosféricas, Efluentes Líquidos e Resíduos}

\begin{tabular}{|c|c|c|c|c|c|c|c|c|c|c|c|c|c|}
\hline \multirow{2}{*}{ PERGUNTA } & \multicolumn{3}{|c|}{2013} & \multicolumn{3}{|c|}{2014} & \multicolumn{3}{|c|}{2015} & \multicolumn{4}{|c|}{2016} \\
\hline & DA & DV & NR & DA & DV & NR & DA & DV & NR & DA & DV & NR & SR \\
\hline $\begin{array}{l}\text { 24. Assinale a alternativa que } \\
\text { caracteriza a condição dos } \\
\text { efluentes líquidos gerados nos } \\
\text { processos produtivos pela } \\
\text { companhia: }\end{array}$ & $56 \%$ & $44 \%$ & $0 \%$ & $39 \%$ & $44 \%$ & $17 \%$ & $39 \%$ & $44 \%$ & $17 \%$ & $28 \%$ & $11 \%$ & $22 \%$ & $39 \%$ \\
\hline $\begin{array}{l}\text { 25. Assinale a alternativa que } \\
\text { caracteriza a condição dos } \\
\text { esgotos domésticos ou efluentes } \\
\text { líquidos gerados nos processos } \\
\text { administrativos pela companhia: }\end{array}$ & $94 \%$ & $0 \%$ & $6 \%$ & $78 \%$ & $6 \%$ & $17 \%$ & $78 \%$ & $6 \%$ & $17 \%$ & $39 \%$ & $0 \%$ & $22 \%$ & $39 \%$ \\
\hline $\begin{array}{l}\text { 26. Assinale a alternativa que } \\
\text { caracteriza a condição das } \\
\text { emissões atmosféricas da } \\
\text { companhia: }\end{array}$ & $89 \%$ & $11 \%$ & $0 \%$ & $78 \%$ & $6 \%$ & $17 \%$ & $67 \%$ & $17 \%$ & $17 \%$ & $33 \%$ & $6 \%$ & $22 \%$ & $39 \%$ \\
\hline $\begin{array}{l}\text { 27. Assinale a alternativa que } \\
\text { indica a prática da companhia } \\
\text { com relação à geração e } \\
\text { destinação de resíduos sólidos: }\end{array}$ & $100 \%$ & $0 \%$ & $0 \%$ & $83 \%$ & $0 \%$ & $17 \%$ & $83 \%$ & $0 \%$ & $17 \%$ & $39 \%$ & $0 \%$ & $22 \%$ & $39 \%$ \\
\hline
\end{tabular}

Fonte: Dados da pesquisa (2017)

Em relação a emissões atmosféricas, efluentes líquidos e Residuais nos anos de 2013, 2014 e 2015 as empresas apresentaram 44\% de divergências entre as respostas e os seus relatórios, visto que muitas empresas não deixaram de forma clara e compreensível esses aspectos em seus relatórios. Entre as empresas que não foi possível observar estes aspectos, estão: Aes Tietê, Centrais Elétricas do Norte do Brasil, CHESF, Cia Geração Térmica de Energia Elétrica, Eletrobrás e Eletrosul.

A Tabela 10 apresenta o Indicador 10 - Emissões e resíduos Críticos. 
Tabela 10 - Indicador 10 - Emissões e Resíduos Críticos

\begin{tabular}{|c|c|c|c|c|c|c|c|c|c|c|c|c|c|}
\hline \multirow{2}{*}{ PERGUNTA } & \multicolumn{3}{|c|}{2013} & \multicolumn{3}{|c|}{2014} & \multicolumn{3}{|c|}{2015} & \multicolumn{4}{|c|}{2016} \\
\hline & DA & DV & NR & DA & DV & NR & DA & DV & NR & DA & DV & NR & SR \\
\hline $\begin{array}{l}\text { 28. A companhia adota } \\
\text { procedimentos específicos para a } \\
\text { gestão de resíduos críticos não } \\
\text { contemplados na legislação e } \\
\text { normas ambientais? }\end{array}$ & $100 \%$ & $0 \%$ & $0 \%$ & $78 \%$ & $6 \%$ & $17 \%$ & $72 \%$ & $11 \%$ & $17 \%$ & $39 \%$ & $0 \%$ & $22 \%$ & $39 \%$ \\
\hline $\begin{array}{l}\text { 29. Assinale a situação da } \\
\text { companhia em relação ao Plano } \\
\text { de Gerenciamento de Resíduos } \\
\text { Sólidos (PGRS): }\end{array}$ & $100 \%$ & $0 \%$ & $0 \%$ & $100 \%$ & $0 \%$ & $0 \%$ & $83 \%$ & $0 \%$ & $17 \%$ & $39 \%$ & $0 \%$ & $22 \%$ & $39 \%$ \\
\hline
\end{tabular}

Legenda: DA: de acordo; DV: divergente; NR: não respondeu; SR: sem relatório.

Fonte: Dados da pesquisa (2017)

Para empresas que operam com atividades que geram resíduos é necessário seguir legislação específica e instaurar algumas ações no cotidiano do processo. Contudo, algumas divergências foram apresentadas nessas duas questões entre as respostas do questionário ISE e o relatório de sustentabilidade, que pode ocorrer devido a serem realizados por pessoas diferentes, ou ainda por não ser amplo o alcance do Programa de Gerenciamento de Resíduos Sólidos na empresa para todos os setores, ou ainda por não ser colocado em prática, tratando-se de documento para manter-se na lei. Tais anseios não são foco desta pesquisa, porém cabe discussão futura.

Na Tabela 10 nota-se que ocorreram divergências na pergunta 28 em 2014 e 2015, visto que as empresas não apresentaram de forma ampla em seu relatório procedimentos que confirmassem a resposta no questionário. No ano de 2014 a pergunta 29 ficou com $0 \%$ em todas as alternativas, pois a pergunta não existia no questionário deste ano.

A Tabela 11 apresenta o Indicador 11 - Segurança Ambiental.

Tabela 11 - Indicador 11 - Seguro Ambiental

\begin{tabular}{|c|c|c|c|c|c|c|c|c|c|c|c|c|c|}
\hline \multirow{2}{*}{ PERGUNTA } & \multicolumn{3}{|c|}{2013} & \multicolumn{3}{|c|}{2014} & \multicolumn{3}{|c|}{2015} & \multicolumn{4}{|c|}{2016} \\
\hline & DA & DV & NR & DA & DV & NR & DA & DV & NR & DA & DV & NR & SR \\
\hline $\begin{array}{l}31 \text { Qual a condição da companhia } \\
\text { em relação as suas áreas de } \\
\text { preservação permanente (APP)? }\end{array}$ & $83 \%$ & $17 \%$ & $0 \%$ & $67 \%$ & $17 \%$ & $17 \%$ & $67 \%$ & $17 \%$ & $17 \%$ & $28 \%$ & $11 \%$ & $22 \%$ & $39 \%$ \\
\hline $\begin{array}{l}32 \text { Indique a situação da } \\
\text { companhia em relação às } \\
\text { coberturas de seguro ambiental } \\
\text { contratadas para suas instalações } \\
\text { e operações: }\end{array}$ & $0 \%$ & $0 \%$ & $0 \%$ & $0 \%$ & $0 \%$ & $0 \%$ & $78 \%$ & $6 \%$ & $17 \%$ & $39 \%$ & $0 \%$ & $22 \%$ & $39 \%$ \\
\hline
\end{tabular}

Legenda: DA: de acordo; DV: divergente; NR: não respondeu; SR: sem relatório.

Fonte: Dados da pesquisa (2017)

A Tabela 11 mostra que nos anos de 2013, 2014 e 2015 17\% das empresas responderam de forma divergente, visto que muitas afirmaram ter áreas de preservação ambiental permanente, porém não apresentaram em seus relatórios indicadores suficientes; muitas dessas, apenas citavam ter áreas de preservação, sem indicar se era permanente ou não, refletindo na falta de padronização nos relatórios das empresas e apresentação transparente, de fácil compreensão e completa. Muitos dos relatórios de sustentabilidade trazem informações que para este estudo, não foram relevantes. 
A pergunta 32 apresentou 0\% nos anos de 2013 e 2014, pois só foi inserida no questionário de 2015.

A Tabela 12 apresenta o Indicador 12 - Área de Preservação Permanente.

Tabela 12 - Indicador 12 - Área de Preservação Permanente

\begin{tabular}{|c|c|c|c|c|c|c|c|c|c|c|c|c|c|}
\hline \multirow{2}{*}{ PERGUNTA } & \multicolumn{3}{|c|}{2013} & \multicolumn{3}{|c|}{2014} & \multicolumn{3}{|c|}{2015} & \multicolumn{4}{|c|}{2016} \\
\hline & DA & DV & NR & DA & DV & NR & DA & DV & NR & DA & DV & NR & SR \\
\hline $\begin{array}{l}\text { 33. Qual a condição das } \\
\text { propriedades rurais da } \\
\text { companhia em relação ao } \\
\text { Cadastro Ambiental Rural } \\
\text { (CAR)? }\end{array}$ & $100 \%$ & $0 \%$ & $0 \%$ & $100 \%$ & $0 \%$ & $0 \%$ & $72 \%$ & $11 \%$ & $17 \%$ & $39 \%$ & $0 \%$ & $22 \%$ & $39 \%$ \\
\hline
\end{tabular}

Legenda: DA: de acordo; DV: divergente; NR: não respondeu; SR: sem relatório.

Fonte: Dados da pesquisa (2017)

$\mathrm{Na}$ análise dos aspectos relativos ao Cadastro Ambiental Rural em 2013 e 2014 estavam $100 \%$ acordadas com os relatórios, já em 2015 e 2016 teve $72 \%$ e 39\% acordadas, respectivamente. Em 2015, 11\% estavam em desacordo, visto que apresentaram resposta sim ao cadastro e em seus relatórios não constava tal informação. Muitas empresas estão se moldando às certificações necessárias, dentro da lei no que diz respeito ao meio ambiente.

A Tabela 13 apresenta o Indicador 13 - Reserva Legal.

Tabela 13 - Indicador 13 - Reserva Legal

\begin{tabular}{|c|c|c|c|c|c|c|c|c|c|c|c|c|c|}
\hline \multirow{2}{*}{ PERGUNTA } & \multicolumn{3}{|c|}{2013} & \multicolumn{3}{|c|}{2014} & \multicolumn{3}{|c|}{2015} & \multicolumn{4}{|c|}{2016} \\
\hline & DA & DV & NR & DA & DV & NR & DA & DV & NR & DA & DV & NR & SR \\
\hline $\begin{array}{l}\text { 34. Qual a situação da companhia } \\
\text { em relação ao licenciamento } \\
\text { ambiental de suas instalações e } \\
\text { processos: }\end{array}$ & $100 \%$ & $0 \%$ & $0 \%$ & $100 \%$ & $0 \%$ & $0 \%$ & $83 \%$ & $0 \%$ & $17 \%$ & $39 \%$ & $0 \%$ & $22 \%$ & $39 \%$ \\
\hline
\end{tabular}

Fonte: Dados da pesquisa (2017)

Legenda: DA: de acordo; DV: divergente; NR: não respondeu; SR: sem relatório.

A Tabela 13 tem evidencia que $100 \%$ das empresas estão em conformidade nos anos de 2013 e 2014. Pode-se inferir que as empresas estão se enquadrando às exigências e cadastros ambientais, em relação aos licenciamentos, questionando até que ponto as empresas evidenciam as suas ações ambientais e divulgam para os seus interessados.

A Tabela 14 apresenta o Indicador 14 - Passivos Ambientais. 
Tabela 14 - Indicador 14 - Passivos Ambientais

\begin{tabular}{|c|c|c|c|c|c|c|c|c|c|c|c|c|c|}
\hline \multirow{2}{*}{ PERGUNTA } & \multicolumn{3}{|c|}{2013} & \multicolumn{3}{|c|}{2014} & \multicolumn{3}{|c|}{2015} & \multicolumn{4}{|c|}{2016} \\
\hline & DA & DV & NR & DA & DV & NR & DA & DV & NR & DA & DV & NR & SR \\
\hline $\begin{array}{l}\text { 35. Nos últimos } 3 \text { anos, a } \\
\text { companhia recebeu alguma } \\
\text { sanção administrativa de } \\
\text { natureza ambiental? }\end{array}$ & $50 \%$ & $50 \%$ & $0 \%$ & $33 \%$ & $50 \%$ & $17 \%$ & $28 \%$ & $56 \%$ & $17 \%$ & $22 \%$ & $17 \%$ & $22 \%$ & $39 \%$ \\
\hline $\begin{array}{l}\text { 35.1. Se SIM para a } \\
\text { PERGUNTA 35, a companhia } \\
\text { possui Termo de Compromisso } \\
\text { de Execução Extrajudicial } \\
\text { assinado neste período? }\end{array}$ & $50 \%$ & $39 \%$ & $11 \%$ & $28 \%$ & $44 \%$ & $28 \%$ & $39 \%$ & $44 \%$ & $17 \%$ & $22 \%$ & $17 \%$ & $22 \%$ & $39 \%$ \\
\hline $\begin{array}{l}\text { 35.1.1. Se SIM para a } \\
\text { PERGUNTA 35.1, a companhia } \\
\text { está inadimplente em relação a } \\
\text { algum compromisso assumido } \\
\text { (prazo ou objeto) em decorrência } \\
\text { da assinatura deste Termo? }\end{array}$ & $44 \%$ & $39 \%$ & $17 \%$ & $33 \%$ & $39 \%$ & $28 \%$ & $29 \%$ & $39 \%$ & $17 \%$ & $22 \%$ & $17 \%$ & $22 \%$ & $39 \%$ \\
\hline
\end{tabular}

Fonte: Dados da pesquisa (2017).

Em relação aos passivos ambientais, a Tabela 14 identifica que muitas empresas apresentaram desacordo para a pergunta número 35 (trinta e cinco) e que obtiveram divergências entre as respostas e os relatórios em 50\% nos anos de 2013 e 2014, 56\% em 2015 e em 2016, embora $39 \%$ não tenham publicado seus relatórios, $17 \%$ estavam divergentes. No que diz respeito a sansões e ações, as empresas não costumam divulgar essas informações em seus relatórios de sustentabilidade, embora em alguns casos apresentassem de forma bem resumida e sem muitos detalhes, que representaram em média 50\% em 2013, 30\% em 2014, 35\% em 2015 e 22\% em 2016.

A Tabela 14 reafirma a existência de falta de informações nos relatórios de sustentabilidade, quando se trata de sanções administrativas, mostrando a falta de transparência e clareza com relação a esses assuntos.

A Tabela 15 apresenta o Indicador 15 - Requisitos Administrativos.

A Tabela 15 foi a que mais apresentou divergências, inferindo que se tratando de aspectos relacionados a processos/ações judiciais, cumprimento a leis e exigências, as empresas divulgaram em seus relatórios pouquíssimas informações que pudessem ser confirmadas neste estudo, conforme proposta de pesquisa. Em 2013, em relação às perguntas 37 (trina e sete), 100\% das empresas apresentaram divergências, justamente pela problemática já justificada anteriormente. As perguntas que apresentaram $0 \%$ em todas as respostas, DA, DV, NR e SR do mesmo ano, significam que a pergunta não estava no questionário do respectivo ano. 
Tabela 15 - Indicador 15 - Requisitos Administrativos

\begin{tabular}{|c|c|c|c|c|c|c|c|c|c|c|c|c|c|}
\hline \multirow{2}{*}{ PERGUNTA } & \multicolumn{3}{|c|}{2013} & \multicolumn{3}{|c|}{2014} & \multicolumn{3}{|c|}{2015} & \multicolumn{4}{|c|}{2016} \\
\hline & DA & DV & NR & DA & DV & NR & DA & DV & NR & DA & DV & NR & SR \\
\hline $\begin{array}{l}\text { 36. Nos últimos } 3 \text { anos, a } \\
\text { companhia sofreu processo } \\
\text { judicial ambiental cível? }\end{array}$ & $50 \%$ & $50 \%$ & $0 \%$ & $33 \%$ & $50 \%$ & $17 \%$ & $33 \%$ & $50 \%$ & $17 \%$ & $22 \%$ & $17 \%$ & $22 \%$ & $39 \%$ \\
\hline $\begin{array}{l}\text { 36.1. Se SIM para a } \\
\text { PERGUNTA } 36, \text { a } \\
\text { companhia foi condenada? }\end{array}$ & $44 \%$ & $56 \%$ & $0 \%$ & $33 \%$ & $50 \%$ & $17 \%$ & $33 \%$ & $50 \%$ & $17 \%$ & $22 \%$ & $17 \%$ & $22 \%$ & $39 \%$ \\
\hline $\begin{array}{l}\text { 36.1.1. Se SIM para a } \\
\text { PERGUNTA 36.1, houve } \\
\text { algum acordo judicial } \\
\text { objetivando a composição } \\
\text { das partes? }\end{array}$ & $50 \%$ & $33 \%$ & $17 \%$ & $28 \%$ & $33 \%$ & $39 \%$ & $28 \%$ & $33 \%$ & $39 \%$ & $28 \%$ & $0 \%$ & $22 \%$ & $50 \%$ \\
\hline $\begin{array}{l}\text { 36.1.1.1. Se SIM para a } \\
\text { PERGUNTA } 36.1 .1 \text {, as } \\
\text { condições da composição } \\
\text { judicial foram cumpridas, ou } \\
\text { estão sendo cumpridas, } \\
\text { dentro dos prazos e critérios } \\
\text { estabelecidos? }\end{array}$ & $44 \%$ & $11 \%$ & $44 \%$ & $72 \%$ & $11 \%$ & $17 \%$ & $28 \%$ & $11 \%$ & $61 \%$ & $22 \%$ & $6 \%$ & $22 \%$ & $50 \%$ \\
\hline $\begin{array}{l}\text { 36.1.1.1.1 Se SIM para a } \\
\text { PERGUNTA 36, houve } \\
\text { acordo(s) judicial(is) } \\
\text { objetivando a composição } \\
\text { das partes, que está(ão) } \\
\text { sendo cumprido(s) dentro } \\
\text { dos prazos e critérios } \\
\text { estabelecidos? }\end{array}$ & $0 \%$ & $0 \%$ & $0 \%$ & $0 \%$ & $0 \%$ & $0 \%$ & $33 \%$ & $50 \%$ & $17 \%$ & $28 \%$ & $11 \%$ & $22 \%$ & $39 \%$ \\
\hline $\begin{array}{l}\text { 37. Nos últimos } 3 \text { anos, a } \\
\text { companhia ou seus } \\
\text { administradores, sofreu } \\
\text { processo judicial ambiental } \\
\text { criminal? }\end{array}$ & $0 \%$ & $100 \%$ & $0 \%$ & $0 \%$ & $83 \%$ & $17 \%$ & $0 \%$ & $83 \%$ & $17 \%$ & $0 \%$ & $39 \%$ & $22 \%$ & $39 \%$ \\
\hline $\begin{array}{l}\text { 37.1. Se SIM para a } \\
\text { PERGUNTA 37, houve } \\
\text { condenação transitada em } \\
\text { julgado? } \\
\text { 37.2. Se SIM para a } \\
\text { PERGUNTA 37, houve } \\
\text { transação ou suspensão } \\
\text { condicional do(s) } \\
\text { processo(s)? }\end{array}$ & $0 \%$ & $100 \%$ & $0 \%$ & $0 \%$ & $83 \%$ & $17 \%$ & $0 \%$ & $83 \%$ & $17 \%$ & $0 \%$ & $39 \%$ & $22 \%$ & $39 \%$ \\
\hline $\begin{array}{l}\text { 37.2.1. Se SIM para a } \\
\text { PERGUNTA 37.2, as } \\
\text { condições da transação } \\
\text { foram cumpridas, ou estão } \\
\text { sendo cumpridas, dentro dos } \\
\text { prazos e critérios } \\
\text { estabelecidos? }\end{array}$ & $0 \%$ & $100 \%$ & $0 \%$ & $0 \%$ & $83 \%$ & $17 \%$ & $0 \%$ & $83 \%$ & $17 \%$ & $0 \%$ & $39 \%$ & $22 \%$ & $39 \%$ \\
\hline $\begin{array}{l}\text { 37.3 Se SIM para a } \\
\text { PERGUNTA } 37, \text { a } \\
\text { companhia divulga os seus } \\
\text { passivos ambientais? }\end{array}$ & $0 \%$ & $100 \%$ & $0 \%$ & $0 \%$ & $83 \%$ & $17 \%$ & $0 \%$ & $83 \%$ & $17 \%$ & $0 \%$ & $39 \%$ & $22 \%$ & $39 \%$ \\
\hline
\end{tabular}




\begin{tabular}{|c|c|c|c|c|c|c|c|c|c|c|c|c|c|}
\hline $\begin{array}{l}37 \text { A companhia possui } \\
\text { passivos ambientais? }\end{array}$ & $0 \%$ & $0 \%$ & $0 \%$ & $0 \%$ & $0 \%$ & $0 \%$ & $61 \%$ & $22 \%$ & $17 \%$ & $28 \%$ & $11 \%$ & $22 \%$ & $39 \%$ \\
\hline $\begin{array}{l}\text { 37.1 Se SIM para a } \\
\text { PERGUNTA } 37 \text {, qual a } \\
\text { previsão para o saneamento } \\
\text { integral desses passivos } \\
\text { ambientais? }\end{array}$ & $0 \%$ & $0 \%$ & $0 \%$ & $0 \%$ & $0 \%$ & $0 \%$ & $33 \%$ & $39 \%$ & $17 \%$ & $22 \%$ & $17 \%$ & $22 \%$ & $39 \%$ \\
\hline $\begin{array}{l}37.2 \text { Se SIM para a } \\
\text { PERGUNTA 37, a } \\
\text { companhia provisionou } \\
\text { recursos financeiros para o } \\
\text { saneamento dos seus } \\
\text { passivos ambientais? }\end{array}$ & $0 \%$ & $0 \%$ & $0 \%$ & $0 \%$ & $0 \%$ & $0 \%$ & $50 \%$ & $22 \%$ & $28 \%$ & $28 \%$ & $11 \%$ & $22 \%$ & $39 \%$ \\
\hline $\begin{array}{l}38 \text { Qual a situação da } \\
\text { companhia em relação ao } \\
\text { licenciamento ambiental de } \\
\text { suas instalações e processos: }\end{array}$ & $0 \%$ & $0 \%$ & $0 \%$ & $56 \%$ & $28 \%$ & $17 \%$ & $56 \%$ & $28 \%$ & $17 \%$ & $17 \%$ & $22 \%$ & $22 \%$ & $39 \%$ \\
\hline
\end{tabular}

Legenda: DA: de acordo; DV: divergente; NR: não respondeu; SR: sem relatório.

Fonte: Dados da pesquisa (2017).

Em 2014 e 2015, em média 50\% das empresas apresentaram divergências em seus relatórios e em 2016 em torno de $25 \%$, mesmo com $39 \%$ de empresas sem seus relatórios divulgados no ano de 2016. Fica evidente em última análise que as empresas, mesmo agindo de forma coerente com os aspectos de compromisso, comportamentos e ações ambientais, nos seus relatórios de sustentabilidade, não evidenciam de forma clara e transparente aspectos que podem apresentar uma imagem negativa e não tão atraente das empresas para os seus investidores e interessados, trazendo um aspecto diferente das demais problemáticas citadas anteriormente.

As poucas informações apresentadas pelas empresas nos relatórios não davam detalhes sobre os seus processos, tão pouco as causas ocasionadas e quais medidas/condutas foram tomaram para solucioná-las.

\section{CONSIDERAÇÕES FINAIS}

O objetivo desta pesquisa foi verificar o nível de evidenciação e coerência entre as informações respondidas pelas empresas que divulgaram suas respostas no ISE com seus relatórios de sustentabilidade.

Para atender ao objetivo, foi necessário coletar as respostas das empresas na carteira ISE e as informações dos relatórios de sustentabilidade das mesmas. Para tanto, foi verificado que algumas empresas divulgaram resposta sim para um ano e resposta não para o outro ano, além disto, muitas respostas eram em percentuais, o que dificultou e limitou a análise. Em relação aos indicadores em percentual, as empresas divulgam em seus relatórios mais a parte financeira da empresa e não o percentual concernente aos níveis organizacionais.

Outro aspecto importante, é a diferença apresentada das respostas de um ano para outro, que acredita-se que ocorreu devido a evolução das empresas em relação ao seu desempenho ambiental ou até mesmo, esses relatórios terem sido respondidos por pessoas diferentes nos anos, apresentando falta de consenso entre os gestores do ISE e do relatório de sustentabilidade, já evidenciado em estudos anteriores como o de Rover et al. (2008), onde apresenta que as empresas podem evidenciar informações negativas de forma voluntária quando acreditam que serão penalizadas pelos usuários externos pela não divulgação, prejudicando a reputação da companhia e desacreditando seus acionistas. Outro ponto é que as últimas 4 (quatro) empresas listadas no 
Quadro 2, que divulgaram as respostas nos anos, se diferem, que pode provocar alterações nos percentuais também.

Em relação ao questionário, ao longo dos anos, aumentou o número de perguntas, a fim de tornar mais completo e compreensível. Nele, as empresas mostram que não costumam evidenciar em seus relatórios de sustentabilidade os quesitos que tratavam sobre as ações/penalidades, permitindo-se questionar sobre o nível de informações divulgadas pelas empresas para seus investidores e interessados, tratando-se de um assunto que muitas vezes pode prejudicar a imagem das mesmas.

Por ser um aspecto de maior exigência nos últimos anos, por parte dos órgãos, acredita-se que muitas empresas tiveram que sofrer grande transformação para se adaptar a essa nova realidade, o que leva a crer que ainda estão em processo de maturação e formalização desses aspectos, embora desde 2005 já exista o ISE e muitas empresas já realizavam o processo de responder o questionário, o que nos leva a acreditar que seria possível ter resultados mais positivos, com as respostas mais próximas das realidades dos relatórios de sustentabilidade.

No que diz respeito a ações ambientais, praticamente todas as empresas responderam de forma positiva, levantando duas hipóteses: as empresas querem passar uma boa imagem para a sociedade e aos seus interessados ou as empresas realmente tiveram uma melhora significante em relação à questão ambiental.

No que se refere aos relatórios, no decorrer dos anos apresentaram-se mais completos e com mais informações, sendo importante para a compreensão de todos os interessados.

Conforme sugestão de Pletsch et al. (2014), o cotejamento das respostas dos questionários das empresas integrantes do ISE com os relatórios de sustentabilidade das mesmas publicados em diferentes períodos, possibilita verificar a evolução dos procedimentos e ações em relação às questões ambientais ao longo do tempo e encontrar discrepâncias na divulgação pelas companhias. Este tipo de estudo, segundo os autores supracitados e de acordo com a pesquisa aqui realizada, contribui com as discussões sobre assimetria na informação, uma vez que diferentes meios de comunicação utilizados pelas empresas podem conter relatos distintos sobre procedimentos ambientais.

Até o mês de maio de 2017, algumas empresas não apresentaram seus relatórios de sustentabilidade referente ao ano de 2016, o que limitou a amostra estudada. Ao solicitar para essas empresas o documento, obtiveram-se respostas de que as mesmas teriam até o último dia do semestre de 2017 para realizar o envio.

\section{REFERÊNCIAS}

BOLSA DE VALORES DE SÃO PAULO (BOVESPA). Mercado: Ações - Índices. 2016. Disponível em: <http://bovespa.com.br>. Acesso em: 14 Mai. 2016.

FEIL, A. A.; NAIME, R. H. Mensuração da sustentabilidade das corporações com selo ISE da BM\&FBOVESPA via modelo GSE. Revista Ambiente Contábil - Universidade Federal do Rio Grande do Norte - ISSN 2176-9036, [S.1.], v. 7, n. 1, p. 254-272, jan. 2015. ISSN 2176-9036. Disponível em: <https://periodicos.ufrn.br/ambiente/article/view/5699/5068>. Acesso em: 05 jun. 2016.

LÓPEZ, M. V.; GARCIA, A.; RODRIGUEZ, L. Desenvolvimento sustentável e desempenho corporativo: um estudo baseado no índice de sustentabilidade Dow Jones. Journal of Business Ethics, v. 75, n. 3, p. 285-300, 2007. 
NOVELINI, C. P.; FREGONESI, M. S. F. A. Análise da divulgação de informações sobre investimentos sociais por empresas que se declaram socialmente responsáveis. Revista de Contabilidade e Organizações, São Paulo, v. 7, n. 17, p. 89-101, jul. 2013. ISSN 1982-6486. Disponível em: <http://www.revistas.usp.br/rco/article/view/56695>. Acesso em: 07 jun 2016. doi:http://dx.doi.org/10.11606/rco.v7i17.56695.

PLETSCH, C. S.; BRIGHETI, J.; DA SILVA, A.; DA ROSA, F. S. Perfil da evidenciação ambiental das empresas listadas no Índice de Sustentabilidade Empresarial. Revista Contabilidade Vista \& Revista, v. 25, n. 3, p. 57-77, 2014. Disponível em: <http://revistas.face.ufmg.br/index.php/contabilidadevistaerevista/article/view/2430>. Acesso em: 06 Abr. 2016.

REZENDE, I. A. C.; NUNES, J. G.; PORTELA, S. S. Um estudo sobre o desempenho financeiro do índice bovespa de sustentabilidade empresarial. Repec - Revista de Educação em Contabilidade, v .2, n. 1, art. 4, p. 71-93, jan./abr.2008. Disponível em: <http://www.repec.org.br/index.php/repec/article/view/22/24>. Acesso em: 05 de abr. 2016.

RIBEIRO, M. S. Contabilidade Ambiental. São Paulo: Saraiva 2005.

ROVER, S.; MURCIA, F. D.; BORBA, J. A.; VICENTE, E. F. R. Divulgação de Informações Ambientais nas Demonstrações Contábeis: Um estudo exploratório sobre o disclosure das empresas brasileiras pertencentes a setores de alto impacto ambiental. Revista de Contabilidade e Organizações, v.3, $\mathrm{n}$ 2, p. 53 - 72 mai./ago.2008. Disponível em: <http://www.redalyc.org/articulo.oa?id=235217220005>. Acesso em: 23 de mai. 2016.

SILVA, J. O.; CUNHA, P. R.; KLANN, R. C.; SCARPIN, J. E. Evidenciação dos custos ambientais nas empresas que compõem o Índice de Sustentabilidade Empresarial (ISE) DOI:10.5007/2175-8069.2010v7n14p159. Revista Contemporânea de Contabilidade, Florianópolis, v. 7, n. 14, p. 159-182, jan. 2011. ISSN 2175-8069. Disponível em: <https://periodicos.ufsc.br/index.php/contabilidade/article/view/2175-

8069.2010v7n14p159/20015>. Acesso em: 07 abr. 2016. doi:http://dx.doi.org/10.5007/21758069.2010v7n14p159.

SZÉKELY, F.; KNIRSCH, M. Responsible leadership and corporate social responsibility: metrics for sustainable performance. European Management Journal, v. 23, n. 6, p. 628-647, 2005. 